\title{
Early Alzheimer's Disease Neuropathology Detected by Proton MR Spectroscopy
}

\author{
일 Melissa E. Murray, ${ }^{1}$ Scott A. Przybelski, ${ }^{2}$ Timothy G. Lesnick, ${ }^{2}$ Amanda M. Liesinger, ${ }^{1}$ Anthony Spychalla, ${ }^{3}$ \\ Bing Zhang, ${ }^{3}$ Jeffrey L. Gunter, ${ }^{3}$ Joseph E. Parisi, ${ }^{4}$ Bradley F. Boeve, ${ }^{5}{ }^{\circ}$ David S. Knopman, ${ }^{5}$ Ronald C. Petersen, ${ }^{5}$ \\ Clifford R. Jack, Jr, ${ }^{3}$ Dennis W. Dickson, ${ }^{1}$ and Kejal Kantarci ${ }^{3}$ \\ ${ }^{1}$ Department of Neuroscience, Mayo Clinic, Jacksonville, Florida 32224, and ${ }^{2}$ Department of Biomedical Statistics, ${ }^{3}$ Department of Radiology, ${ }^{4}$ Department \\ of Pathology, and ${ }^{5}$ Department of Neurology, Mayo Clinic, Rochester, Minnesota 55905
}

Proton magnetic resonance spectroscopy $\left({ }^{1} \mathrm{H}-\mathrm{MRS}\right)$ is sensitive to early neurodegenerative processes associated with Alzheimer's disease (AD). Although ${ }^{1} \mathrm{H}$-MRS metabolite ratios of $N$-acetyl aspartate (NAA)/creatine (Cr), NAA/myoinositol (mI), and mI/Cr measured in the posterior cingulate gyrus reveal evidence of disease progression in $\mathrm{AD}$, pathologic underpinnings of the ${ }^{1} \mathrm{H}$-MRS metabolite changes in $\mathrm{AD}$ are unknown. Pathologically diagnosed human cases ranging from no likelihood to high likelihood $\mathrm{AD}(n=41,16$ females and 25 males) who underwent antemortem ${ }^{1} \mathrm{H}$-MRS of the posterior cingulate gyrus at 3 tesla were included in this study. Immunohistochemical evaluation was performed on the posterior cingulate gyrus using antibodies to synaptic vesicles, hyperphosphorylated tau (pTau), neurofibrillary tangle conformational-epitope ( $\mathrm{cNFT}$ ), amyloid- $\beta$, astrocytes, and microglia. The slides were digitally analyzed using Aperio software, which allows neuropathologic quantification in the posterior cingulate gray matter. MRS and pathology associations were adjusted for time from scan to death. Significant associations across AD and control subjects were found between reduced synaptic immunoreactivity and both NAA/Cr and NAA/mI in the posterior cingulate gyrus. Higher pTau burden was associated with lower NAA/Cr and NAA/mI. Higher amyloid- $\beta$ burden was associated with elevated $\mathrm{mI} / \mathrm{Cr}$ and lower NAA/mI ratios, but not with NAA/Cr. ${ }^{1} \mathrm{H}-\mathrm{MRS}$ metabolite levels reveal early neurodegenerative changes associated with $\mathrm{AD}$ pathology. Our findings support the hypothesis that a decrease in NAA/Cr is associated with loss of synapses and early pTau pathology, but not with amyloid- $\beta$ or later accumulation of cNFT pathology in the posterior cingulate gyrus. In addition, elevation of $\mathrm{mI} / \mathrm{Cr}$ is associated with the occurrence of amyloid- $\beta$ plaques in AD.

Key words: Alzheimer's disease; digital microscopy; magnetic resonance spectroscopy; neuropathology; posterior cingulate; tau

\section{Introduction}

The utilization of neuroimaging as an Alzheimer's disease (AD) biomarker has been included in the most recent National Insti-

Received May 19, 2014; revised Sept. 24, 2014; accepted 0ct. 18, 2014.

Author contributions: M.E.M. and K.K. designed research; M.E.M., A.M.L., A.S., B.Z., J.L.G., J.E.P., B.F.B., D.S.K., R.C.P., C.R.J., D.W.D., and K.K. performed research; S.A.P. and T.G.L. analyzed data; M.E.M. and K.K. wrote the paper.

All patients or their informants signed consent to disclosure of clinical information, neuroimaging, and brain donation with appropriate ethical approval from the Mayo Clinic Institutional Review Board.

This work was supported by the National Institutes of Health (Grants R01-AG040042, R01-AG011378, P50AG016574/P1, and U01-AG006786), the Mangurian Foundation, and the Robert H. and Clarice Smith and Abigail van Buren AD Research Program. We thank the patients and their families who have participated in these prospective clinical and imaging studies, especially for the generous donation of their brain tissue to help further our knowledge in Alzheimer's disease. We also acknowledge the continuous commitment and teamwork offered by Linda G. Rousseau, Virginia R. Phillips, and Monica Castanedes-Casey and thank Kris Johnson for assistance in collection of pathologic material. M.E.M. is an associate editor for BMC Neurology. J.E.P. receives publishing royalties for Principles \& Practice of Neuropathology, Ed 2. B.F.B. has served as an investigator for clinical trials sponsored by Cephalon, Allon Pharmaceuticals, and GE Healthcare; receives royalties from the publication of Behavioral Neurology of Dementia; has received honoraria from the American Academy of Neurology; serves on the Scientific Advisory Board of the Tau Consortium; and receives research support from the National Institute on Aging, National Institutes of Health [Grant P50 AG16574 (coinvestigator), Grant U01 AG06786 (coinvestigator), Grant R01 AG15866 (coinvestigator) and Grant U24 AG26395 (coinvestigator)] and the Alzheimer's Association [Grant IIRG-05-14560 (principal investigator)]. D.S.K. serves as an associate editor for Neurology; serves on a data safety monitoring board for Lilly Pharmaceuticals; is an investigator in a clinical trial sponsored by Janssen Pharmaceuticals; and receives research support from the National Institutes of Health [Grant R01-AG11378 (coinvestigator), Grant P50 AG16574 (coinvestigator), and Grant U01 AG 006786 (coinvestigator). R.C.P. serves on scientific advisory boards for Elan Pharmaceuticals, Wyeth Pharmaceuticals, and GE Healthcare; receives royalties from Mild Cognitive Impairment; and receives research support from the National Institutes of Health [Grant P50-AG16574 (primary investigator), Grant U01-AG06786 (primary tute on Aging-Alzheimer's Association (NIA-AA) consensus recommendations on diagnostic guidelines (Albert et al., 2011; Jack et al., 2011; McKhann et al., 2011). Atrophy on structural MRI, especially of medial temporal lobe structures, is an accepted biomarker for the clinical and neuropathologic progression of $\mathrm{AD}$ (Jack et al., 1992; Jack et al., 2002; Whitwell et al., 2008). However, structural changes evident on MRI occur once loss or shrinkage of neurons and synapses has already begun. Therefore,

investigator), and Grant R01-AG11378 (coinvestigator). C.R.J. provides consulting services for Siemens Healthcare and receives research funding from the National Institutes of Health (Grants R01-AG011378, R01-AG041851, R01AG037551, U01-HL096917, U01-AG032438, and U01-AG024904) and the Alexander Family Alzheimer's Disease Research Professorship of the Mayo Foundation. D.W.D. is an editorial board member of American Journal of Pathology, Annals of Neurology, Parkinsonism and Related Disorders, Journal of Neuropathology and Experimental Neurology, and Brain Pathology; is editor-in-chief of the American Journal of Neurodegenerative Disease and the International Journal of Clinical and Experimental Pathology; and receives research support from the National Institutes of Health [Grant P50 AG016574 (coinvestigator), Grant P50 NS072187 (principal investigator) and the CurePSP/Society for Progressive Supranuclear Palsy. K.K. serves on the data safety monitoring board for Pfizer Janssen Alzheimer Immunotherapy, Takeda Global Research \& Development Center; and receives research support from the National Institutes of Health [Grant R01AG040042 (principal investigator), Mayo Clinic Alzheimer's Disease Research Center/Project 1 Grant P50 AG16574/P1 (principal investigator), Grant P50 AG44170/Project 2 (principal investigator), and Grant R01 AG11378 (coinvestigator)]. S.A.P., T.G.L., A.M.L., A.S., B.Z., and J.L.G. declare no competing financial interests.

Correspondence should be addressed to Kejal Kantarci, MD, MS, Mayo Clinic, 200 First Street SW, Rochester, MN 55905. E-mail: kantarci.keja@@mayo.edu.

DOI:10.1523/JNEUROSCI.2027-14.2014

Copyright $\odot 2014$ the authors $\quad 0270-6474 / 14 / 3416247-09 \$ 15.00 / 0$ 

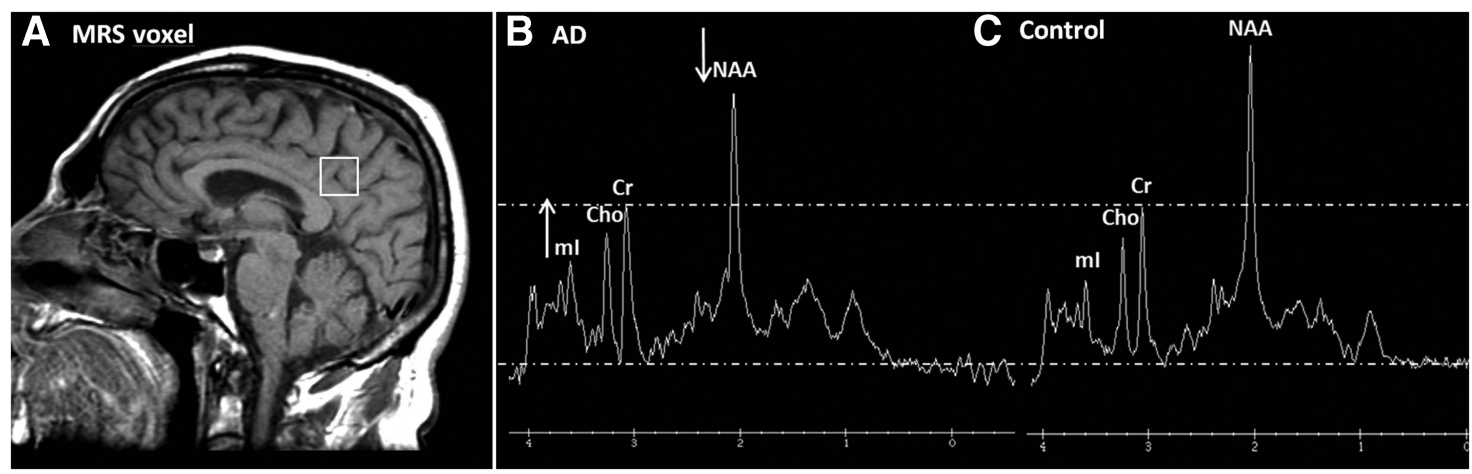

Figure 1. A, Placement of the ${ }^{1} \mathrm{H}-\mathrm{MRS}$ voxel on a midsagittal $\mathrm{T} 1$ weighted image. The $8 \mathrm{~cm}^{3}$ voxel is covering right and left hemispheric posterior cingulate gyri and inferior precunei. Examples of proton spectra obtained from the posterior cingulate voxel with an echo time of $30 \mathrm{~ms}$ in $\boldsymbol{B}$, an AD patient, and in $C$, a control subject. The NAA/Cr and NAA/ml ratio is lower and the ml/Cr ratio is higher in the patient with AD than the control subject. All spectra are scaled to the height of the reference peak $\mathrm{Cr}$ for demonstration of the differences in ratios to $\mathrm{Cr}$.

a biomarker that could detect early changes before neuronal death would be a highly effective option for tracking early disease progression for identifying patients for preclinical interventions.

Proton magnetic resonance spectroscopy $\left({ }^{1} \mathrm{H}-\mathrm{MRS}\right)$ is a noninvasive neuroimaging technique that quantitatively measures metabolite changes associated with AD-type pathology (Ross et al., 1998; Kantarci et al., 2008). ${ }^{1} \mathrm{H}-\mathrm{MRS}$ measurements of the metabolite $\mathrm{N}$-acetylaspartate (NAA) and the ratio of NAA to the reference metabolite creatine (NAA/Cr) longitudinally decrease over the course of $\mathrm{AD}$ dementia and mild cognitive impairment (Adalsteinsson et al., 2000). Conversely, an elevation in myoinositol (mI) and the $\mathrm{mI} / \mathrm{Cr}$ ratio are observed earlier compared with NAA metabolite changes in the disease course (Miller et al., 1993; Kantarci et al., 2000; Catani et al., 2001; Bartha et al., 2008; Schott et al., 2010). These ${ }^{1} \mathrm{H}$-MRS changes have been shown to associate with the global neuropathologic scores of amyloid- $\beta$ plaque severity and neurofibrillary tangle stage (Kantarci et al., 2008). However, the local histopathologic findings underlying these metabolite alterations in $\mathrm{AD}$ are unknown.

Decreased glucose metabolism from positron emission tomography (PET) studies of the posterior cingulate gyrus have shown this region to be involved early in $\mathrm{AD}$ dementia (Herholz et al., 2002). Moreover, the posterior cingulate gyrus has readily definable neuroanatomical landmarks and importantly does not suffer from susceptibility artifacts and lipid contamination on MRS related to proximity to the skull and sinuses. A multivoxel MRS study demonstrated that the short echo-time spectra in the posterior cingulate have a higher quality compared with the temporal lobe voxel (Kantarci et al., 2000; Ebel et al., 2001). ${ }^{1} \mathrm{H}$-MRS findings have supported evaluation of the posterior cingulate gyrus, having demonstrated differential metabolite measurements across $\mathrm{AD}$, dementia with Lewy bodies, frontotemporal dementia, and healthy elderly controls (Kantarci, 2007). The posterior cingulate gyrus exhibits dysfunction in mild symptomatic AD dementia (Brun and Gustafson, 1976; Vogt et al., 1990; Liu et al., 1996; Vogt et al., 1998). These observations underscore the rationale for selecting the posterior cingulate gyrus to investigate the relationship between MRS metabolite changes with abnormal biological underpinnings.

We sought to examine the specific regional correlates between antemortem ${ }^{1} \mathrm{H}$-MRS metabolite measurements and AD-related neuropathologic immunoreactivity (i.e., burden) in the posterior cingulate gyrus of a cohort with a range of $\mathrm{AD}$ pathology using quantitative digital microscopy. We used immunohistochemical markers to measure synaptic vesicle loss and accumulation of amyloid- $\beta$, phospho-tau ("early" tau pathology; neurites, pre- tangles, mature tangles), neurofibrillary tangle conformational specific antibodies ("late" tau pathology; mature and extracellular tangles), microglia, and astrocytes to investigate the neuropathologic basis of ${ }^{1} \mathrm{H}$-MRS metabolite alterations associated with $\mathrm{AD}$ dementia.

\section{Materials and Methods}

Design. Consecutive patients with an antemortem ${ }^{1} \mathrm{H}-\mathrm{MRS}$ performed at 3 tesla MRI who came to autopsy were selected from both the Mayo Clinic Alzheimer Disease Research Center, a dementia clinic cohort, and the Mayo Clinic Study of Aging, a longitudinal population-based cohort (Roberts et al., 2008). Case selection was performed based on neuropathologic diagnosis and not antemortem clinical diagnosis. Neuroimaging studies were performed on a total 138 autopsied patients between $10 / 24 / 2005$ until $4 / 28 / 2011$, with the first autopsy performed 11/1/2006 and the last on 2/9/2012 at the ADRC Neuropathology Core. Neuroimaging exclusion criteria were as follows: (1) presence of structural abnormalities that could impact ${ }^{1} \mathrm{H}$-MRS measurements such as brain tumors and stroke or (2) illnesses or treatments interfering with cognitive function other than $\mathrm{AD}$ at the time of ${ }^{1} \mathrm{H}$-MRS. Of the remaining 127 patients that came to autopsy, the posterior cingulate gyrus was sampled in 80 of the brains. Neuropathology exclusion criteria were as follows: (1) hippocampal sclerosis or frontotemporal lobar degeneration, (2) tauopathies (progressive supranuclear palsy, corticobasal degeneration, and neurofibrillary tangle predominant dementia), and (3) and Lewy body disease. Amygdala predominant Lewy body cases were not excluded, however, because it is considered an isolated amygdala $\alpha$-synucleinopathy found frequently in neuropathologically diagnosed $\mathrm{AD}$ brains (Uchikado et al., 2006). The final study cohort included 41 autopsied individuals ( 25 men and 16 women; age at death 51-101 years) who had a range of AD-type pathologies but no other substantial disease processes.

MRI and ${ }^{1} H$-MRS. All subjects underwent MRI and ${ }^{1} \mathrm{H}-\mathrm{MRS}$ studies on a 3 tesla scanner using an 8-channel phased array coil (GE Healthcare) within a median of 2.0 years before death. ${ }^{1} \mathrm{H}$-MRS studies were performed using the automated single-voxel MRS package (PROBE/ SV; GE Healthcare) (Webb et al., 1994). A trained imaging technician placed an $8 \mathrm{~cm}^{3}(2 \times 2 \times 2 \mathrm{~cm})$ voxel on a midsagittal T1-weighted image over the medial parietal posterior cingulate. The splenium of the corpus callosum was used for the anterior inferior corner, and the cingulate sulcus was used for the anterior superior corner of the voxel. The voxel covered the right and left posterior cingulate gyri and inferior precunei (posterior cingulate voxel) (Fig. 1). ${ }^{1} \mathrm{H}$-MRS examinations were performed using the point-resolved spectroscopy (PRESS) pulse sequence with TR $=2000$ $\mathrm{ms}, \mathrm{TE}=30 \mathrm{~ms}, 2048$ data points, and 128 excitations. PROBE's prescan algorithm makes automatic adjustments to the transmitter and receiver gains and center frequency. Before PRESS acquisition, the flip angle of the third water suppression pulse was adjusted for chemical shift water suppression (CHESS). At the end of each PROBE/SV acquisition, metabolite intensity ratios were automatically calculated using a previously validated algorithm (Webb et al., 1994). MRS metabolite ratios that were 
Table 1. Patient characteristics

\begin{tabular}{|c|c|c|c|}
\hline & $\begin{array}{l}\text { No to low } \\
\text { likelihood of AD } \\
(n=17)\end{array}$ & $\begin{array}{l}\text { Intermediate to high } \\
\text { likelihood of AD } \\
(n=24)\end{array}$ & $p$ \\
\hline Females (\%) & $5(29)$ & $11(46)$ & 0.29 \\
\hline APOE $\varepsilon 4$ carriers (\%) & $1(6)$ & $14(58)$ & $<0.001$ \\
\hline Age at scan, y & $87(82,89)$ & $82(70.5,85.5)$ & 0.03 \\
\hline Education, y & $14(12,16)$ & $16(12,18)$ & 0.34 \\
\hline CDR sum of boxes & $0.0(0.0,0.0)$ & $5.5(0.75,9.5)$ & $<0.001$ \\
\hline $\begin{array}{l}\text { Time to death from } \\
\text { scan (yrs.) }\end{array}$ & $1.56(0.65,3.06)$ & $2.42(1.12,3.57)$ & 0.12 \\
\hline \multicolumn{4}{|l|}{ Clinical diagnosis } \\
\hline Normal & 15 & 2 & $<0.001$ \\
\hline $\mathrm{MCl}$ & 2 & 6 & \\
\hline Probable AD & 0 & 13 & \\
\hline DLB & 0 & 2 & \\
\hline $\begin{array}{l}\text { Progressive visual } \\
\text { dysfunction }\end{array}$ & 0 & 1 & \\
\hline $\mathrm{NAA} / \mathrm{Cr}^{\prime}$ & $1.72(1.64,1.76)$ & $1.56(1.49,1.64)$ & 0.006 \\
\hline $\mathrm{Cho} / \mathrm{Cr}$ & $0.67(0.61,0.73)$ & $0.69(0.65,0.72)$ & 0.50 \\
\hline $\mathrm{ml} / \mathrm{Cr}$ & $0.50(0.47,0.55)$ & $0.58(0.52,0.64)$ & 0.04 \\
\hline $\mathrm{NAA} / \mathrm{ml}$ & $3.20(2.91,3.71)$ & $2.72(2.44,3.11)$ & 0.004 \\
\hline Neurons/mm² & $144.15(134.87,159.19)$ & $147.93(128.21,154.01)$ & 0.40 \\
\hline Synaptic, \% ir. & $93(91,93)$ & $91(90,93)$ & 0.07 \\
\hline pTau, \% burden & $0.02(0.01,0.02)$ & $8.00(1.09,14.01)$ & $<0.001$ \\
\hline cNFT, $\%$ burden & $0.06(0.03,0.09)$ & $0.21(0.12,0.68)$ & $<0.001$ \\
\hline Total $A \beta, \%$ burden & $0.10(0.07,0.73)$ & $1.32(0.84,2.54)$ & $<0.001$ \\
\hline "Diffuse" $A \beta, \%$ burden & $0.09(0.07,0.57)$ & $1.04(0.67,1.57)$ & $<0.001$ \\
\hline "Cored" $A \beta, \%$ burden & $0.00(0.00,0.11)$ & $0.27(0.14,0.77)$ & $<0.001$ \\
\hline Microglia, \% burden & $0.26(0.19,0.35)$ & $0.40(0.29,0.50)$ & 0.002 \\
\hline Astrocyte, \% burden & $22(16,26)$ & $33(26,42)$ & $<0.001$ \\
\hline
\end{tabular}

Median $(25,75$ th interquartile range) reported for the continuous variables and number (\%) for the categorical variables.

CDR, Clinical dementia rating scale; DLB, dementia with Lewy bodies.

analyzed for this study included NAA/Cr, choline (Cho)/Cr, $\mathrm{mI} / \mathrm{Cr}$ and $\mathrm{NAA} / \mathrm{mI}$.

Neuropathologic examinations. Standardized methods for sampling and neuropathologic examination were performed according to the The Consortium to Establish a Registry for Alzheimer's Disease and the Third Report of the Dementia with Lewy bodies Consortium (Mirra et al., 1991; McKeith et al., 2005). Braak neurofibrillary tangle (NFT) stage was determined based on the distribution of NFTs assessed with Bielschowsky silver stain (Braak and Braak, 1991). The likelihood of a subject having $\mathrm{AD}$ was judged to not meet criteria or be low, intermediate, or high, according to the NIA-Reagan Institute Working Group criteria (Hyman and Trojanowski, 1997). Table 1 shows the separation of normal pathologic controls (i.e., criteria not met or low likelihood of $\mathrm{AD}$ ) and $\mathrm{AD}$ cases (i.e., intermediate and high likelihood of AD) using the NIA-Reagan criteria.

Serial 5- $\mu \mathrm{m}$-thick sections of the posterior cingulate were immunostained on a DAKO Autostainer (Universal Staining System) using 3,3'diaminobenzidine $(\mathrm{DAB})$ as the chromogen. Immunohistochemical evaluation of neuropathology using antibodies to detect a phospho-tau (pTau) epitope that labels early neuritic and NFT pathology, including pretangles (CP13, mouse IgG1, 1:1000, generous gift from Peter Davies, Albert Einstein College of Medicine, Bronx, NY), a conformational epitope in NFTs (cNFT) labeling late-stage tangles (Ab39, monoclonal, 1:350, gift from Shu-Hui Yen, Mayo Clinic, Jacksonville, FL) (Yen et al., 1987), amyloid- $\beta$ (33.1.1, 1:1000, human A $\beta 1-16$ specific, gift from Pritam Das, Mayo Clinic, Jacksonville, FL), microglia (CD68, mouse IgG1, 1:1000, Dako), astrocyte (glial fibrillary acidic protein [GFAP], mouse IgG1, 1:5000; Biogenex). Synaptic vesicles were also immunohistochemically evaluated using an antibody to SV2A (mouse IgG1, Abcam). SV2A is a synaptic vesicle protein that has been implicated as a target site for the anti-epileptic drug levetiracetam (Lynch et al., 2004), and recently evaluated as a potential therapeutic target in mild cognitive impairment (MCI) (Bakker et al., 2012). Afterward, the sections were counterstained with hematoxylin. In addition, a section was stained with hematoxylin and eosin (H\&E) to quantify the density of pyramidal neurons in the posterior cingulate. Digital microscopy methods have been previously described (Murray et al., 2011; Janocko et al., 2012), but briefly, slides were analyzed using Aperio digital microscopy hardware and software (Aperio Technologies, Vista, CA) and then analyzed using four customdesigned positive-pixel count ImageScope algorithms (Ab39, SV2A, 33.1.1, and GFAP), two color deconvolution algorithms (CP13 and CD68) and one nuclear algorithm for neuronal count (H\&E). Therefore, immunoreactivity will be referred to as "burden," given the quantitative approach using image analysis. The positive pixel count algorithm uses the hue-saturation-intensity model that can be modified to stains of interest. It is useful for stains that have light and intense staining properties of interest or for stains that label a large fraction of the annotated area. The color deconvolution algorithm detects the positive pixels using optical density as input parameters, converts these to a percentage burden of the total area annotated. Figure 2 illustrates the intensity markup images with red=positive pixels, yellow=background pixels (except for amyloid- $\beta$ ), and blue $=$ negative pixels. The percentage area of burden in the amyloid- $\beta$ stain uses the tinctorial properties of the diffuse (yellow pixels) and neuritic or cored amyloid (red pixels). The neuronal count algorithm uses the optical density of the neuronal cytoplasm to identify the cell of interest, but the optimum elongation parameter also detects endothelial cells. To remove these, a second algorithm with the same input parameters other than pixel size is used to subtract the endothelial cells and other small cells that interfere with quantification. All neuropathologic analyses were performed blinded to metabolite ratios.

Statistical analysis. We summarized patient characteristics using medians and interquartile ranges along with the unadjusted $p$-values from two-sided, two-sample Wilcoxon rank sum tests for the continuous variables. For categorical variables, we summarized the counts of subjects as well as the percents and $p$-values from $\chi^{2}$ tests. We calculated partial Spearman rank correlations between imaging and pathology variables, after adjusting for time from MRI scan to death. The residual of the ranks of the two variables are compared after linear regression on the ranks of the controlled variable. As age is highly correlated with disease progression, age was excluded as a covariate in statistical analyses to prevent collinearity masking significant correlations. This study was designed to assess specific a priori selected biologically relevant hypotheses. Since each was of individual interest, we did not want to inflate the individual type II errors, nor limit ourselves to a general null hypothesis that all null hypotheses were simultaneously true. Accordingly, we did not adjust for multiple comparisons (Rothman, 1990; Perneger, 1998). However, we do report the results of all of the tests, allowing readers to reach their own conclusions. A $p$-value $<0.05$ was considered statistically significant.

\section{Results}

The demographic and clinical aspects of patients are shown in Table 1. The no-likelihood to low-likelihood AD group were clinically diagnosed as normal or MCI at the time of MRI. The majority of the intermediate- to high-likelihood $\mathrm{AD}$ group was diagnosed as MCI or probable AD dementia (79\%). Two of the intermediate-likelihood AD cases clinically diagnosed as cognitively normal were found to have a Braak NFT stage IV and moderate neuritic plaques at autopsy. Two high-likelihood AD cases clinically diagnosed as dementia with Lewy bodies were both found to have frequent plaques, one of which had a Braak stage $\mathrm{V}$ with no coexisting pathology and the second had a Braak stage V-VI with amygdala predominant Lewy bodies. Three other high-likelihood $\mathrm{AD}$ cases clinically diagnosed as probable $\mathrm{AD}$ were found to have amygdala predominant Lewy bodies. It is considered an isolated amygdala $\alpha$-synucleinopathy and can be found frequently in neuropathologically diagnosed $\mathrm{AD}$ brains (Uchikado et al., 2006) and therefore was not used as an exclusion criteria.

Neuronal density did not differ between the AD likelihood groups stratified in Table 1, but synaptic vesicle immunoreac- 


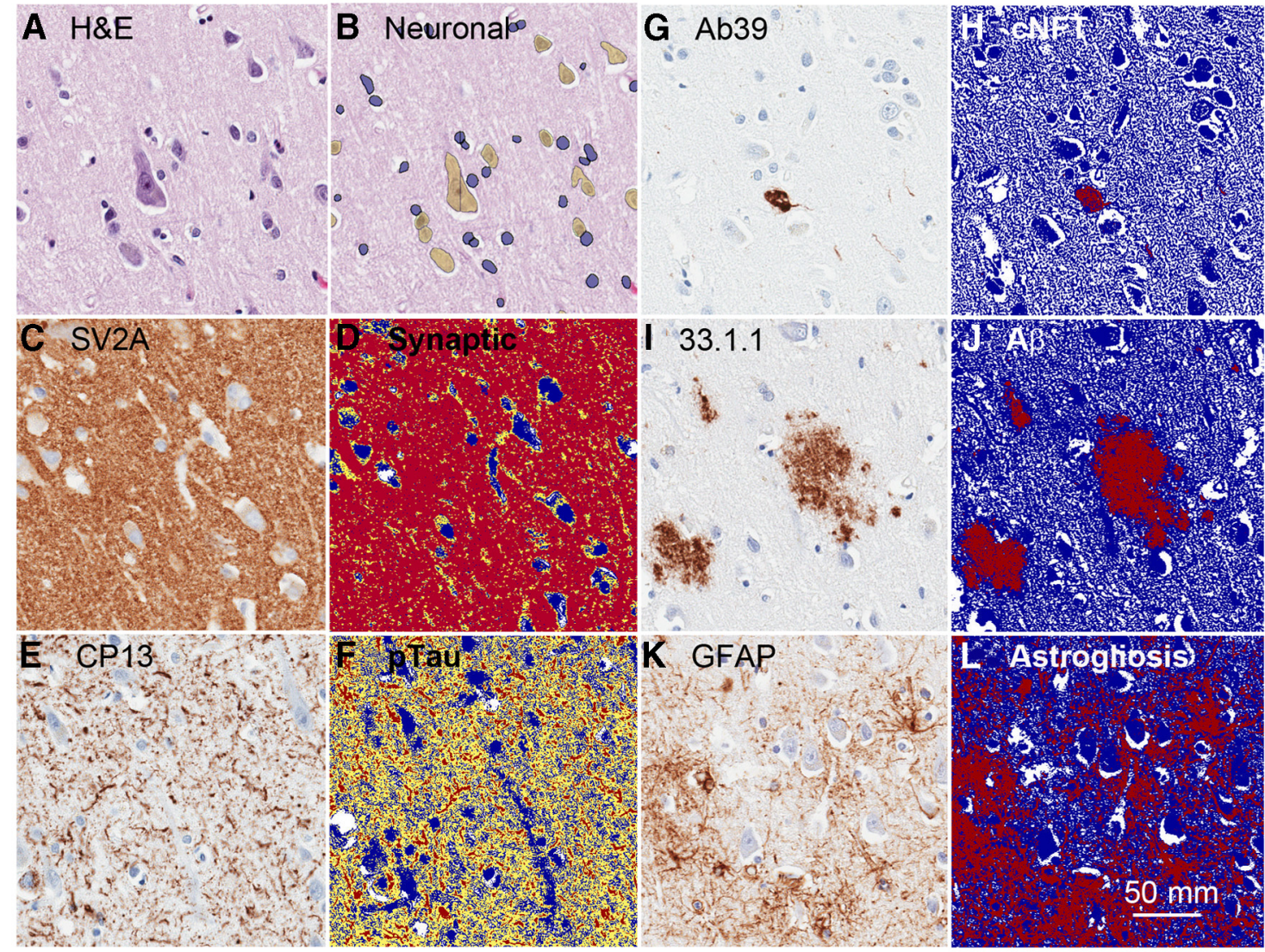

Figure 2. Serial sections of the posterior cingulate were immunostained, scanned, traced, and analyzed to obtain neuronal density and neuropathologic burden across AD and normal brains. The entirety of the posterior cingulate was traced in ImageScope and then analyzed using custom-designed algorithms. The photomicrographs are labeled with stain or antibody used with adjoining markup images postanalysis. $\boldsymbol{A}$, H\&E slides, pictured top left, were used to assess neuronal density $(\boldsymbol{B})$ where the yellow markup image positively assed the neurons and the blue markup identifies glial cells. Using custom-designed color deconvolution algorithm to identify positive immunostain in red, background in yellow, and negative pixels in blue, the SV2A antibody was used to detect immunoreactivity of synaptic vesicles $(\boldsymbol{E}, \boldsymbol{F})$ and the (P13 antibody was used to detect hyperphosphorylated tau $(\boldsymbol{I}, \boldsymbol{J})$. The positive pixel count was customized to quantify brown immunoreactive lesions (red markup), considering all other pixels negative (blue). C, D, The Ab39 antibody was used to detect conformational epitope to neurofibrillary tangles (CNFT). 33.1 .1 was used as a pan-A $\beta$ marker $(\boldsymbol{G}, \boldsymbol{H})$ and GFAP was used to detect astrogliosis $(\boldsymbol{K}, \boldsymbol{L})$. All are shown at $20 \times$ zoom.

tivity showed a trend of lower levels in the intermediate- to high-likelihood AD group (Fig. 3). Quantitative measures of accumulated pTau, cNFT, and amyloid- $\beta$ and markers of microglial and astrocytic burden differed between the $\mathrm{AD}$ likelihood groups. Neuropathologic pTau burden increased nearly 40 -fold from Braak NFT stage III to IV (0.03\% to $1.0 \%)$, increased nearly 9-fold from Braak NFT stage IV to V (1.0\% to 9.2\%) and nearly tripled from Braak NFT stage V to VI $(9.2 \%$ to $28 \%$; $p<0.001)$. Neuropathologic cNFT burden did not differ from Braak NFT stage III to IV $(0.09 \%$ to $0.08 \%)$, increased 2.5 -fold from Braak NFT stage IV to $\mathrm{V}(0.08 \%$ to $0.21 \%)$, and increased 6 -fold from Braak NFT stage V to VI $(0.20 \%$ to $1.2 \%$; $p<$ $0.001)$. Neuropathologic amyloid- $\beta$ burden increased nearly 13 -fold from Braak NFT stage III to IV (0.10\% to $1.3 \%)$, increased 1.4-fold from Braak NFT stage IV to V ( $1.3 \%$ to $1.9 \%)$, and decreased 1.5-fold from Braak NFT stage V to VI (1.9\% to $1.2 \% ; p=0.003$ ).

$\mathrm{NAA} / \mathrm{Cr}$ and $\mathrm{NAA} / \mathrm{mI}$ metabolite ratios were lower in the intermediate- to high-likelihood group compared with the nolikelihood to low-likelihood group, whereas $\mathrm{mI} / \mathrm{Cr}$ was higher (Table 1). Cho/Cr ratios did not differ between groups. Figure $1 B$ shows an example of spectra obtained from the posterior cingulate voxel of a clinically probable $\mathrm{AD}$ patient with advanced $\mathrm{AD}$ neuropathology and a cognitively normal subject found to have no significant pathology at autopsy.
Table 2 displays the Spearman rank correlations performed across the spectrum of no-likelihood to high-likelihood cases, with significant correlations shown in Figure 4. The NAA/Cr and $\mathrm{NAA} / \mathrm{mI}$ ratios from the posterior cingulate voxel significantly associated with synaptic vesicle immunoreactivity in the posterior cingulate gyrus after adjusting for time from scan to death. Therefore, the higher the NAA metabolite ratios (i.e., closer to normal), the greater the percentage area of synaptic immunoreactivity (i.e., the more SV2A-immunoreactive synaptic vesicles were intact). No association was found between synaptic vesicle immunoreactivity and $\mathrm{Cho} / \mathrm{Cr}$ and $\mathrm{mI} / \mathrm{Cr}$ ratios. Reduced synaptic vesicle immunoreactivity was associated with greater accumulation of neuropathologic measures of pTau $(r=-0.41, p=0.009)$, cNFT $(r=-0.44, p=0.004)$, but not with amyloid- $\beta$, microglia, or astrocyte markers. pTau burden was inversely associated with $\mathrm{NAA} / \mathrm{Cr}$ and NAA/mI, but not with Cho/Cr. pTau burden also showed a trend of association with $\mathrm{mI} / \mathrm{Cr}$, but this was not statistically significant $(p=0.07)$. Interestingly, cNFT burden (a marker of late extracellular NFT pathology) did not associate with any of the metabolite ratios. Amyloid- $\beta$ burden significantly associated with $\mathrm{mI} / \mathrm{Cr}$ and inversely with $\mathrm{NAA} / \mathrm{mI}$. CD68positive microglia did not associate with any of the metabolite ratios. GFAP-positive astrocytic burden approached significance with a trend of inverse association with $\mathrm{NAA} / \mathrm{Cr}$ and $\mathrm{NAA} / \mathrm{mI}$, but this was not statistically significant. 


\section{Low-likelihood of AD High-likelihood of AD Low-likelihood of AD High-likelihood of AD}

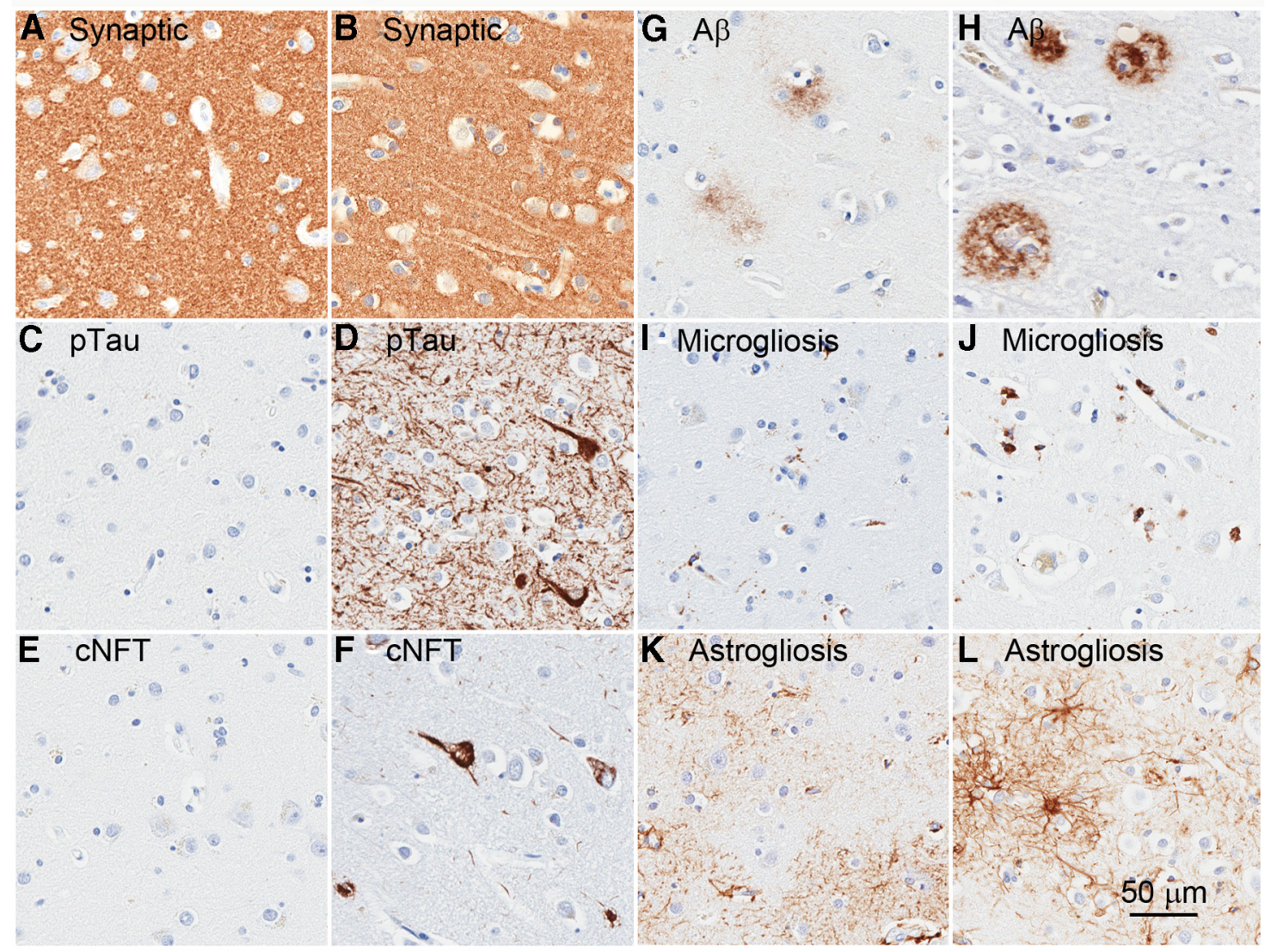

Figure 3. Photomicrographs from representative cases classified as low and high likelihood of AD. $\boldsymbol{A}, \boldsymbol{B}$, Using SV2A immunohistochemistry to detect synaptic immunoreactivity in the posterior cingulate showed subtle differences between groups. C, D, CP13 antibody was used to detect "early" pTau pathology, immunolabeling neurites, pretangles, and mature tangles. pTau was rarely seen in low-likelihood AD cases, but frequently observed in high-likelihood AD cases. $\boldsymbol{E}, \boldsymbol{F}$, Ab39 is a neurofibrillary tangle conformational specific antibody that detects "late" tau pathology (cNFT), immunolabeling mature and extracellular tangles. CNFT pathology was not seen in low-likelihood cases, but moderately to frequently observed in high-likelihood AD. $\boldsymbol{G}, \boldsymbol{H}$, Diffuse plaques were more commonly found in low-likelihood AD cases using a pan-A $\beta$ antibody compared with more frequent compact and cored plaques in high-likelihood AD cases. $I, J$, Microgliosis was detected with a CD68 antibody revealing higher numbers of CD68-positive microglia in high-likelihood cases. $K, \boldsymbol{L}$, GFAP immunoreactive astrocytes were observed in both low- and high-likelihood AD cases, but in higher abundance in high-likelihood AD. All are shown at $20 \times$ zoom.

Table 2. Spearman rank correlations adjusted for time from scan to death across the entire cohort of neuropathologically diagnosed healthy and AD spectrum subjects $(n=41)$

\begin{tabular}{|c|c|c|c|c|c|c|c|c|}
\hline & \multicolumn{2}{|l|}{$\mathrm{NAA} / \mathrm{Cr}$} & \multicolumn{2}{|l|}{$\mathrm{Cho} / \mathrm{Cr}$} & \multicolumn{2}{|l|}{$\mathrm{ml} / \mathrm{Cr}$} & \multicolumn{2}{|l|}{$\mathrm{NAA} / \mathrm{ml}$} \\
\hline & Rho (95\% Cl) & $p$ & Rho (95\% Cl) & $p$ & Rho (95\% Cl) & $p$ & Rho $(95 \%$ Cl) & $p$ \\
\hline Neurons $/ \mathrm{mm}^{2}$ & $0.19(-0.14,0.47)$ & 0.26 & $-0.05(-0.36,0.27)$ & 0.76 & $-0.14(-0.43,0.19)$ & 0.40 & $0.13(-0.19,0.43)$ & 0.42 \\
\hline Synaptic, \% ir. & $0.32(0.00,0.57)$ & 0.05 & $0.08(-0.24,0.38)$ & 0.64 & $-0.26(-0.53,0.06)$ & 0.10 & $0.31(-0.01,0.56)$ & 0.05 \\
\hline pTau, $\%$ burden & $-0.35(-0.60,-0.04)$ & 0.02 & $0.04(-0.28,0.34)$ & 0.83 & $0.29(-0.03,0.55)$ & 0.07 & $-0.36(-0.60,-0.05)$ & 0.02 \\
\hline cNFT, \% burden & $-0.23(-0.50,0.09)$ & 0.15 & $0.04(-0.27,0.35)$ & 0.80 & $0.17(-0.15,0.45)$ & 0.30 & $-0.19(-0.47,0.13)$ & 0.25 \\
\hline Total $A \beta, \%$ burden & $-0.19(-0.47,0.13)$ & 0.23 & $0.22(-0.10,0.49)$ & 0.18 & $0.37(0.06,0.61)$ & 0.02 & $-0.36(-0.60,-0.05)$ & 0.02 \\
\hline "Diffuse" $A \beta, \%$ burden & $-0.25(-0.52,0.07)$ & 0.12 & $0.19(-0.14,0.47)$ & 0.25 & $0.32(0.01,0.58)$ & 0.04 & $-0.34(-0.59,-0.03)$ & 0.03 \\
\hline "Cored" $A \beta, \%$ burden & $-0.14(-0.43,0.18)$ & 0.38 & $0.22(-0.10,0.50)$ & 0.16 & $0.38(0.07,0.61)$ & 0.02 & $-0.35(-0.59,-0.04)$ & 0.03 \\
\hline Microglia, \% burden & $-0.25(-0.52,0.07)$ & 0.12 & $0.05(-0.27,0.35)$ & 0.77 & $0.15(-0.17,0.44)$ & 0.35 & $-0.26(-0.52,0.06)$ & 0.11 \\
\hline Astrocyte, \% burden & $-0.29(-0.55,0.02)$ & 0.06 & $-0.11(-0.41,0.21)$ & 0.48 & $0.21(-0.11,0.49)$ & 0.19 & $-0.30(-0.56,0.01)$ & 0.06 \\
\hline
\end{tabular}

\section{Discussion}

MRS detected early biochemical changes associated with AD neuropathology in the posterior cingulate gyrus. We demonstrated an association between the NAA/Cr metabolite ratio and both reduced synaptic vesicle immunoreactivity and accumulation of early intracellular and neuritic pTau pathology. Conversely, the $\mathrm{mI} / \mathrm{Cr}$ ratio was found to associate with accumulation of amyloid- $\beta$ pathology. A relationship with both pTau and amyloid- $\beta$ pathology were observed when the two metabolite ratios were combined to form the $\mathrm{NAA} / \mathrm{mI}$ ratio, emphasizing the complementary relationship of these two metabolites as an in vivo diagnostic marker of $\mathrm{AD}$-related pathology.

NAA content is mainly regulated by the mitochondrial synthesis rate and less by the rate of neuronal release or NAA oxidation (Bates et al., 1996; Petroff et al., 2003). Therefore, NAA is considered to be a marker of neuronal viability and not necessarily neuronal loss. The association we found between NAA/Cr and synaptic vesicle immunoreactivity but not neuronal density further indicates that NAA/Cr is a marker of synaptic integrity in $\mathrm{AD}$. The decrease of the NAA/Cr ratio reported in $\mathrm{MCI}$ and $\mathrm{AD}$ 
A

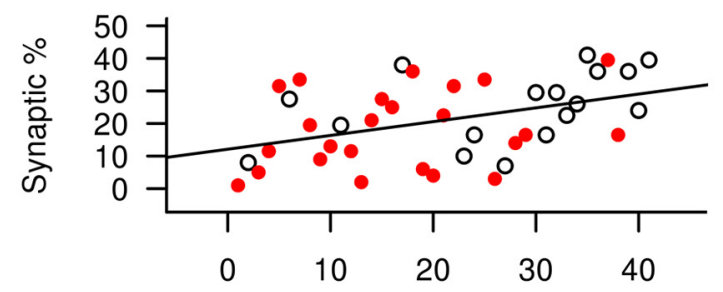

$\mathrm{NAA} / \mathrm{Cr}$

C

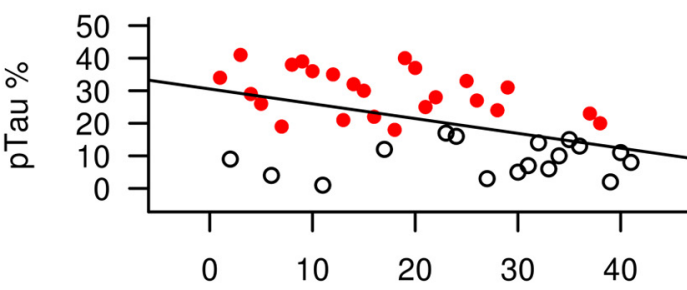

$\mathrm{NAA} / \mathrm{Cr}$

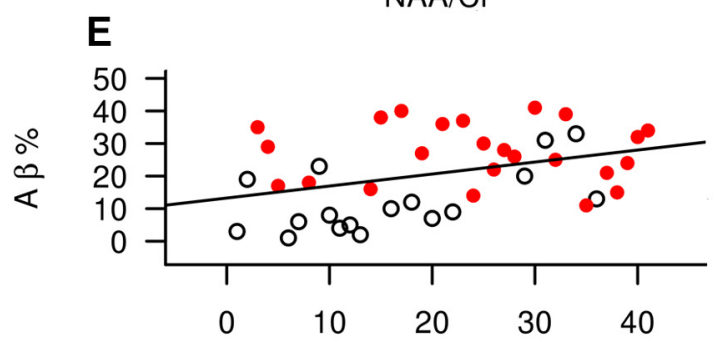

$\mathrm{ml} / \mathrm{Cr}$

G

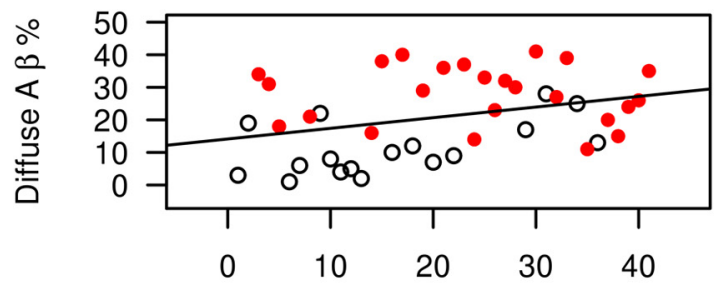

$\mathrm{ml} / \mathrm{Cr}$

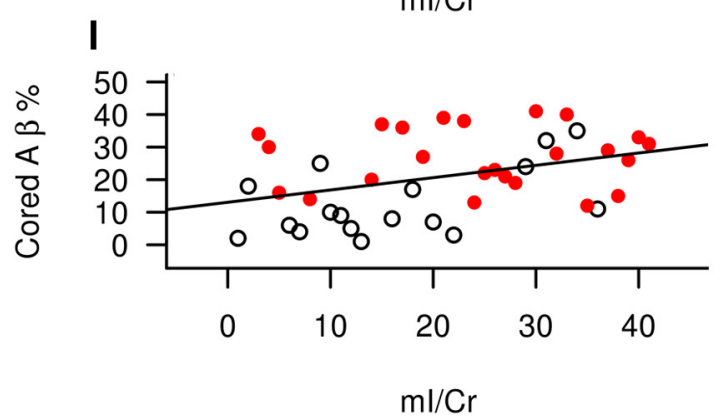

B

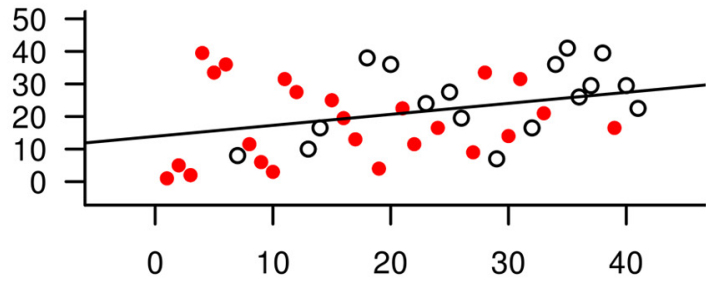

$\mathrm{NAA} / \mathrm{ml}$

D

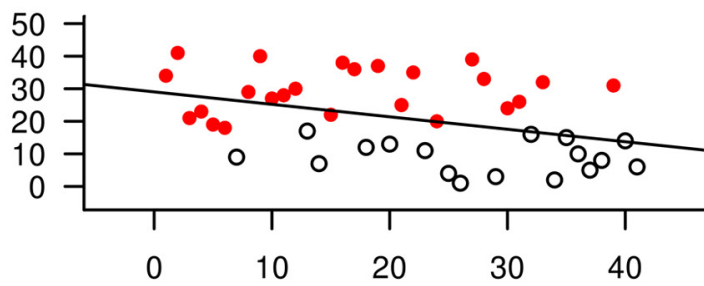

$\mathrm{NAA} / \mathrm{ml}$

F

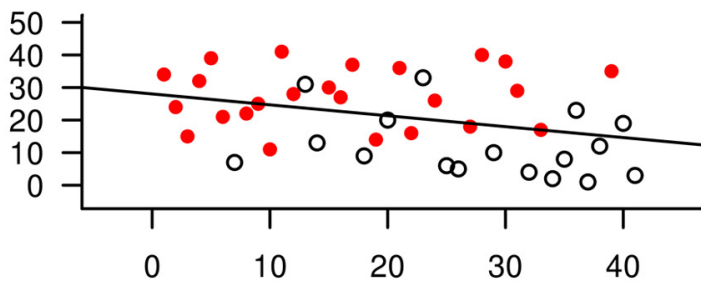

$\mathrm{NAA} / \mathrm{ml}$

H

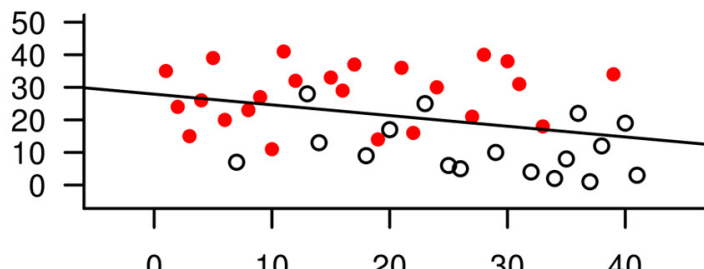

$\mathrm{NAA} / \mathrm{m}$
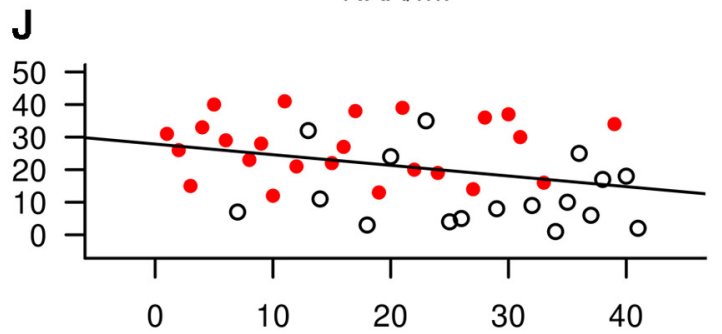

$\mathrm{NAA} / \mathrm{ml}$

Figure 4. Significant correlations between antemortem MR spectroscopy metabolite ratios from the posterior cingulate ( $x$-axis) and corresponding neuropathologic measures ( $y$-axis) are plotted as residuals. The highest value is ranked as 1, the next highest 2, etc. $\boldsymbol{A}, \boldsymbol{B}, \mathrm{A}$ higher NAA/Cr ratio correlated with higher synaptic immunoreactivity $(\boldsymbol{A})$ but inversely correlated with pTau ( $\boldsymbol{B})$ showing minimal overlap between no likelihood to low likelihood and intermediate to high likelihood. A higher $\mathrm{ml} /(\mathrm{Cr}$ ratio correlated with higher total $A \beta$ burden $(\boldsymbol{C})$, diffuse $A \beta$ burden $(\boldsymbol{D})$, and cored A $\beta$ burden (E). NAA/ml combines the two metabolites of interest, revealing significant correlations that were observed in both NAA/ $\mathrm{Cr}(\boldsymbol{F}, \boldsymbol{G})$ and $\mathrm{ml} / \mathrm{Cr}(\boldsymbol{H}-\boldsymbol{J})$.

dementia was significantly associated with early neuritic, pretangle, and mature tangle pathology (pTau) and not with extracellular tangle pathology (cNFT) that appears later. This finding underlies early NAA/Cr metabolite changes on MRS before irre- versible neuronal damage. Early-stage tau pathology is a dynamic process involving the accumulation of hyperphosphorylated tau species that form diffuse intracellular neuronal inclusions (i.e., pretangles labeled by pTau) (Goedert et al., 1989; Iqbal and 
Grundke-Iqbal, 1991) that accumulate in the dendrites and axons and are considered to further perturb neuronal function. As the neuronal tau protein continues to be hyperphosphorylated, along with other posttranslational modifications, the inclusion continues to mature before the eventual death of the neuron (i.e., extracellular NFT labeled by cNFT; Yen et al., 1987). The extracellular NFT acts as a tombstone or remnant of a once-living neuron that has succumbed to neurofibrillary degeneration and is no longer a dynamic process as the neuronal death has occurred. Our study demonstrates for the first time an observed association of lower NAA/Cr with worsened synaptic integrity and higher pTau, but not with neuronal loss or cNFT. Collectively, these findings further support our hypothesis that NAA/Cr is a marker of early tau-mediated dynamic processes in $\mathrm{AD}$.

Although the NAA/Cr is decreased in AD dementia, $\mathrm{mI} / \mathrm{Cr}$ is found to be elevated (Miller et al., 1993). The mI metabolite is considered to be a glial metabolite marker (Glanville et al., 1989; Bitsch et al., 1999), thus prompting our investigation into its relationship with neuropathologic burden of GFAP-positive astrocytes and CD68-positive microglia. We did not find an association with increasing $\mathrm{mI}$ even though both GFAP and CD68 burdens were higher in the intermediate- to high-likelihood AD group. Bitsch et al. described a relationship between astroglial pathology and $\mathrm{mI}$ levels in a small sample with inflammatory CNS demyelination (Bitsch et al., 1999). They described elevated $\mathrm{mI}$ was more pronounced in areas with more severe gliosis. The lack of association between GFAP and $\mathrm{mI} / \mathrm{Cr}$ in the present study could relate to technical differences in measurement of GFAP burden or other factors arising during inflammatory demyelination (Oz et al., 2010). Further lack of an association with CD68positive microglia and $\mathrm{mI}$, however, suggests that there is not a relationship between $\mathrm{mI}$ elevation and gliosis in $\mathrm{AD}$.

The results from the present study validate our previous findings that showed an association of $\mathrm{mI} / \mathrm{Cr}$ with the global staging of amyloid- $\beta$ plaque pathology (Kantarci et al., 2008) and with amyloid- $\beta$ load on PET (Kantarci et al., 2011). These results further emphasize that greater accumulation of amyloid associates with abnormal elevations in $\mathrm{mI} / \mathrm{Cr}$, but not with lower NAA/Cr metabolite ratios (Kantarci et al., 2011). In an effort to distinguish whether diffuse plaques or cored/neuritic plaques drove this relationship, we used the tinctorial staining properties to assess lightly stained diffuse amyloid- $\beta$ pathology versus the more intensely stained cored/neuritic amyloid- $\beta$ pathology. We found a significant relationship with $\mathrm{mI} / \mathrm{Cr}$ for both types of plaques. Diffuse plaques can be found in cognitively normal elderly and in pathological aging brains upon microscopic inspection (Morris et al., 1996; Murray and Dickson, 2014). Diffuse plaques highly correlate with both cored and neuritic plaques, both of which appear densely stained by the amyloid- $\beta$ marker. One interpretation of our findings is that increasing amyloid- $\beta$ burden may indiscriminately affect $\mathrm{mI}$ regardless of morphological classification. Alternatively, more sophisticated double-staining techniques may need to be performed to interpret the relevant importance of the neuritic plaque burden because these are considered the more deleterious amyloid- $\beta$ plaque. A more recent study investigating passive immunization with amyloid- $\beta$ antibodies in the APP/PS1 mouse model found an attenuation of the increased $\mathrm{mI} / \mathrm{Cr}$ ratio in the treated mice compared with placebo (Marjańska et al., 2014), supporting an $\mathrm{mI} / \mathrm{Cr}$ association with amyloid- $\beta$ and its utility in therapeutic trials targeting amyloid- $\beta$ pathology.

The Cho/Cr metabolite ratio is thought to represent membrane turnover because the choline peak is considered to be the breakdown products of phosphatidylcholine-one of the principle components of the cell membrane's phospholipid bilayer (Klein, 2000). Changes in the $\mathrm{Cho/Cr}$ ratio in AD dementia have inconsistently been reported to be elevated (Pfefferbaum et al., 1999; Kantarci et al., 2004) or show no change (Moats et al., 1994; Schuff et al., 1997; Rose et al., 1999; Krishnan et al., 2003). In the present study, we did not find a difference in $\mathrm{Cho/Cr}$ when cases were stratified by AD likelihood. We also found no association with any of the neuropathologic measures.

Time to death from scans did not significantly differ among the neuropathologic groups, but still varied across the patients. Furthermore, our adjusted Spearman correlations using regression analysis did not allow us to take into account nonlinearity of MRS between time of scan and death. For these reasons, we accounted for this variability in all correlative data by adjusting for time to death from scan. Quantitative analysis of ${ }^{1} \mathrm{H}$-MRS metabolites were performed using the manufacturer's PROBE software, which is available on clinical scanners (Webb et al., 1994). This automated software package has been shown to reliably reproduce metabolite values, even when compared with more analytically sophisticated LCModel software (Fayed et al., 2009). Donepezil may also influence MRS metabolite measurements, putatively influencing increased synaptic activity with an associated decrease in NAA/Cr (Krishnan et al., 2003). As expected, the majority of the intermediate- to high-likelihood $\mathrm{AD}$ cases were being treated with acetylcholinesterase inhibitors. Should the treatment have had an effect, it would have only worked to minimize the associations that were observed.

This study provides quantitative evidence that MRS can detect early changes differentially associated with both pTau and amyloid- $\beta$ pathologies of $\mathrm{AD}$. MRS is a noninvasive, inexpensive and efficient neuroimaging tool that does not require injection of radiotracers to monitor metabolic changes in the brain. Given these apparent benefits and data presented in this study, MRS should be considered as imaging biomarker for the staging of preclinical $\mathrm{AD}$ and as a surrogate marker in therapeutic trials targeting $\mathrm{AD}$-related protein deposits.

\section{References}

Adalsteinsson E, Sullivan EV, Kleinhans N, Spielman DM, Pfefferbaum A (2000) Longitudinal decline of the neuronal marker $\mathrm{N}$-acetyl aspartate in Alzheimer's disease. Lancet 355:1696-1697. CrossRef Medline

Albert MS, DeKosky ST, Dickson D, Dubois B, Feldman HH, Fox NC, Gamst A, Holtzman DM, Jagust WJ, Petersen RC, Snyder PJ, Carrillo MC, Thies B, Phelps CH (2011) The diagnosis of mild cognitive impairment due to Alzheimer's disease: recommendations from the National Institute on Aging-Alzheimer's Association workgroups on diagnostic guidelines for Alzheimer's disease. Alzheimers Dement 7:270-279. CrossRef Medline

Bakker A, Krauss GL, Albert MS, Speck CL, Jones LR, Stark CE, Yassa MA, Bassett SS, Shelton AL, Gallagher M (2012) Reduction of hippocampal hyperactivity improves cognition in amnestic mild cognitive impairment. Neuron 74:467-474. CrossRef Medline

Bartha R, Smith M, Rupsingh R, Rylett J, Wells JL, Borrie MJ (2008) High field (1)H MRS of the hippocampus after donepezil treatment in Alzheimer disease. Prog Neuropsychopharmacol Biol Psychiatry 32:786-793. CrossRef Medline

Bates TE, Strangward M, Keelan J, Davey GP, Munro PM, Clark JB (1996) Inhibition of $\mathrm{N}$-acetylaspartate production: implications for $1 \mathrm{H}$ MRS studies in vivo. Neuroreport 7:1397-1400. CrossRef Medline

Bitsch A, Bruhn H, Vougioukas V, Stringaris A, Lassmann H, Frahm J, Brück W (1999) Inflammatory CNS demyelination: histopathologic correlation with in vivo quantitative proton MR spectroscopy. AJNR Am J Neuroradiol 20:1619-1627. Medline

Braak H, Braak E (1991) Neuropathological stageing of Alzheimer-related changes. Acta neuropathologica 82:239-259. CrossRef Medline

Brun A, Gustafson L (1976) Distribution of cerebral degeneration in Alzhei- 
mer's disease. A clinico-pathological study. Arch Psychiatr Nervenkr 223: 15-33. CrossRef Medline

Catani M, Cherubini A, Howard R, Tarducci R, Pelliccioli GP, Piccirilli M, Gobbi G, Senin U, Mecocci P (2001) (1)H-MR spectroscopy differentiates mild cognitive impairment from normal brain aging. Neuroreport 12:2315-2317. CrossRef Medline

Ebel A, Soher BJ, Maudsley AA (2001) Assessment of 3D proton MR echoplanar spectroscopic imaging using automated spectral analysis. Magn Reson Med 46:1072-1078. CrossRef Medline

Fayed N, Modrego PJ, Medrano J (2009) Comparative test-retest reliability of metabolite values assessed with magnetic resonance spectroscopy of the brain. The LCModel versus the manufacturer software. Neurol Res 31: 472-477. CrossRef Medline

Glanville NT, Byers DM, Cook HW, Spence MW, Palmer FB (1989) Differences in the metabolism of inositol and phosphoinositides by cultured cells of neuronal and glial origin. Biochimica et Biophysica Acta 1004: 169-179. CrossRef Medline

Goedert M, Spillantini MG, Potier MC, Ulrich J, Crowther RA (1989) Cloning and sequencing of the cDNA encoding an isoform of microtubuleassociated protein tau containing four tandem repeats: differential expression of tau protein mRNAs in human brain. EMBO J 8:393-399. Medline

Herholz K, Salmon E, Perani D, Baron JC, Holthoff V, Frölich L, Schönknecht P, Ito K, Mielke R, Kalbe E, Zündorf G, Delbeuck X, Pelati O, Anchisi D, Fazio F, Kerrouche N, Desgranges B, Eustache F, Beuthien-Baumann B, Menzel C, Schröder J, Kato T, Arahata Y, Henze M, Heiss WD (2002) Discrimination between Alzheimer dementia and controls by automated analysis of multicenter FDG PET. Neuroimage 17:302-316. CrossRef Medline

Hyman BT, Trojanowski JQ (1997) Consensus recommendations for the postmortem diagnosis of Alzheimer disease from the National Institute on Aging and the Reagan Institute Working Group on diagnostic criteria for the neuropathological assessment of Alzheimer disease. J Neuropathol Exp Neurol 56:1095-1097. CrossRef Medline

Iqbal K, Grundke-Iqbal I (1991) Ubiquitination and abnormal phosphorylation of paired helical filaments in Alzheimer's disease. Mol Neurobiol 5:399-410. CrossRef Medline

Jack CR Jr, Petersen RC, O’Brien PC, Tangalos EG (1992) MR-based hippocampal volumetry in the diagnosis of Alzheimer's disease. Neurology 42:183-188. CrossRef Medline

Jack CR Jr, Dickson DW, Parisi JE, Xu YC, Cha RH, O'Brien PC, Edland SD, Smith GE, Boeve BF, Tangalos EG, Kokmen E, Petersen RC (2002) Antemortem MRI findings correlate with hippocampal neuropathology in typical aging and dementia. Neurology 58:750-757. CrossRef Medline

Jack CR Jr, Albert MS, Knopman DS, McKhann GM, Sperling RA, Carrillo MC, Thies B, Phelps CH (2011) Introduction to the recommendations from the National Institute on Aging-Alzheimer's Association workgroups on diagnostic guidelines for Alzheimer's disease. Alzheimers Dement 7:257-262. CrossRef Medline

Janocko NJ, Brodersen KA, Soto-Ortolaza AI, Ross OA, Liesinger AM, Duara R, Graff-Radford NR, Dickson DW, Murray ME (2012) Neuropathologically defined subtypes of Alzheimer's disease differ significantly from neurofibrillary tangle-predominant dementia. Acta Neuropathologica 124:681-692. CrossRef Medline

Kantarci K (2007) $1 \mathrm{H}$ magnetic resonance spectroscopy in dementia. Br J Radiol 80:S146-S152. CrossRef Medline

Kantarci K, Jack CR Jr, Xu YC, Campeau NG, O’Brien PC, Smith GE, Ivnik RJ, Boeve BF, Kokmen E, Tangalos EG, Petersen RC (2000) Regional metabolic patterns in mild cognitive impairment and Alzheimer's disease: A 1H MRS study. Neurology 55:210-217. CrossRef Medline

Kantarci K, Petersen RC, Boeve BF, Knopman DS, Tang-Wai DF, O’Brien PC, Weigand SD, Edland SD, Smith GE, Ivnik RJ, Ferman TJ, Tangalos EG, Jack CR Jr (2004) 1H MR spectroscopy in common dementias. Neurology 63:1393-1398. CrossRef Medline

Kantarci K, Knopman DS, Dickson DW, Parisi JE, Whitwell JL, Weigand SD, Josephs KA, Boeve BF, Petersen RC, Jack CR Jr (2008) Alzheimer disease: postmortem neuropathologic correlates of antemortem $1 \mathrm{H}$ MR spectroscopy metabolite measurements. Radiology 248:210-220. CrossRef Medline

Kantarci K, Lowe V, Przybelski SA, Senjem ML, Weigand SD, Ivnik RJ, Roberts R, Geda YE, Boeve BF, Knopman DS, Petersen RC, Jack CR Jr (2011) Magnetic resonance spectroscopy, beta-amyloid load, and cognition in a population-based sample of cognitively normal older adults. Neurology 77:951-958. CrossRef Medline

Klein J (2000) Membrane breakdown in acute and chronic neurodegeneration: focus on choline-containing phospholipids. J Neural Transm 107: 1027-1063. CrossRef Medline

Krishnan KR, Charles HC, Doraiswamy PM, Mintzer J, Weisler R, Yu X, Perdomo C, Ieni JR, Rogers S (2003) Randomized, placebo-controlled trial of the effects of donepezil on neuronal markers and hippocampal volumes in Alzheimer's disease. Am J Psychiatry 160:2003-2011. CrossRef Medline

Liu X, Erikson C, Brun A (1996) Cortical synaptic changes and gliosis in normal aging, Alzheimer's disease and frontal lobe degeneration. Dementia 7:128-134. Medline

Lynch BA, Lambeng N, Nocka K, Kensel-Hammes P, Bajjalieh SM, Matagne A, Fuks B (2004) The synaptic vesicle protein SV2A is the binding site for the antiepileptic drug levetiracetam. Proc Natl Acad Sci U S A 101: 9861-9866. CrossRef Medline

Marjańska M, Weigand SD, Preboske G, Wengenack TM, Chamberlain R, Curran GL, Poduslo JF, Garwood M, Kobayashi D, Lin JC, Jack CR Jr (2014) Treatment effects in a transgenic mouse model of Alzheimer's disease: A magnetic resonance spectroscopy study after passive immunization. Neuroscience 259:94-100. CrossRef Medline

McKeith IG, Dickson DW, Lowe J, Emre M, O’Brien JT, Feldman H, et al; Consortium on DLB. (2005) Diagnosis and management of dementia with Lewy bodies: third report of the DLB Consortium. Neurology 65: 1863-1872. CrossRef Medline

McKhann GM, Knopman DS, Chertkow H, Hyman BT, Jack CR Jr, Kawas CH, Klunk WE, Koroshetz WJ, Manly JJ, Mayeux R, Mohs RC, Morris JC, Rossor MN, Scheltens P, Carrillo MC, Thies B, Weintraub S, Phelps CH (2011) The diagnosis of dementia due to Alzheimer's disease: recommendations from the National Institute on Aging-Alzheimer's Association workgroups on diagnostic guidelines for Alzheimer's disease. Alzheimers Dement 7:263-269. CrossRef Medline

Miller BL, Moats RA, Shonk T, Ernst T, Woolley S, Ross BD (1993) Alzheimer disease: depiction of increased cerebral myo-inositol with proton $M R$ spectroscopy. Radiology 187:433-437. CrossRef Medline

Mirra SS, Heyman A, McKeel D, Sumi SM, Crain BJ, Brownlee LM, Vogel FS, Hughes JP, van Belle G, Berg L (1991) The Consortium to Establish a Registry for Alzheimer's Disease (CERAD). Part II. Standardization of the neuropathologic assessment of Alzheimer's disease. Neurology 41:479486. CrossRef Medline

Moats RA, Ernst T, Shonk TK, Ross BD (1994) Abnormal cerebral metabolite concentrations in patients with probable Alzheimer disease. Magn Reson Med 32:110-115. CrossRef Medline

Morris JC, Storandt M, McKeel DW Jr, Rubin EH, Price JL, Grant EA, Berg L (1996) Cerebral amyloid deposition and diffuse plaques in "normal" aging: Evidence for presymptomatic and very mild Alzheimer's disease. Neurology 46:707-719. CrossRef Medline

Murray ME, Dickson DW (2014) Is pathological aging a successful resistance against amyloid-beta or preclinical Alzheimer's disease? Alzheimers Res Ther 6:24. CrossRef Medline

Murray ME, Graff-Radford NR, Ross OA, Petersen RC, Duara R, Dickson DW (2011) Neuropathologically defined subtypes of Alzheimer's disease with distinct clinical characteristics: a retrospective study. Lancet Neurol 10:785-796. CrossRef Medline

Oz G, Nelson CD, Koski DM, Henry PG, Marjanska M, Deelchand DK, Shanley R, Eberly LE, Orr HT, Clark HB (2010) Noninvasive detection of presymptomatic and progressive neurodegeneration in a mouse model of spinocerebellar ataxia type 1. J Neurosci 30:3831-3838. CrossRef Medline

Perneger TV (1998) What's wrong with Bonferroni adjustments. BMJ 316 : 1236-1238. CrossRef Medline

Petroff OA, Errante LD, Kim JH, Spencer DD (2003) N-acetyl-aspartate, total creatine, and myo-inositol in the epileptogenic human hippocampus. Neurology 60:1646-1651. CrossRef Medline

Pfefferbaum A, Adalsteinsson E, Spielman D, Sullivan EV, Lim KO (1999) In vivo spectroscopic quantification of the $N$-acetyl moiety, creatine, and choline from large volumes of brain gray and white matter: effects of normal aging. Magnetic Resonance in Medicine 41:276-284. CrossRef Medline

Roberts RO, Geda YE, Knopman DS, Cha RH, Pankratz VS, Boeve BF, Ivnik RJ, Tangalos EG, Petersen RC, Rocca WA (2008) The Mayo Clinic Study 
of Aging: design and sampling, participation, baseline measures and sample characteristics. Neuroepidemiology 30:58-69. CrossRef Medline

Rose SE, de Zubicaray GI, Wang D, Galloway GJ, Chalk JB, Eagle SC, Semple J, Doddrell DM (1999) A 1H MRS study of probable Alzheimer's disease and normal aging: implications for longitudinal monitoring of dementia progression. Magn Reson Imaging 17:291-299. CrossRef Medline

Ross BD, Bluml S, Cowan R, Danielsen E, Farrow N, Tan J (1998) In vivo MR spectroscopy of human dementia. Neuroimaging Clin North Am 8:809-822. Medline

Rothman KJ (1990) No adjustments are needed for multiple comparisons. Epidemiology 1:43-46. CrossRef Medline

Schott JM, Frost C, MacManus DG, Ibrahim F, Waldman AD, Fox NC (2010) Short echo time proton magnetic resonance spectroscopy in Alzheimer's disease: a longitudinal multiple time point study. Brain 133: 3315-3322. CrossRef Medline

Schuff N, Amend D, Ezekiel F, Steinman SK, Tanabe J, Norman D, Jagust W, Kramer JH, Mastrianni JA, Fein G, Weiner MW (1997) Changes of hippocampal $\mathrm{N}$-acetyl aspartate and volume in Alzheimer's disease. A proton MR spectroscopic imaging and MRI study. Neurology 49:1513-1521. CrossRef Medline

Uchikado H, Lin WL, DeLucia MW, Dickson DW (2006) Alzheimer disease with amygdala Lewy bodies: a distinct form of alpha-synucleinopathy. J Neuropathol Exp Neurol 65:685-697. CrossRef Medline

Vogt BA, Van Hoesen GW, Vogt LJ (1990) Laminar distribution of neuron degeneration in posterior cingulate cortex in Alzheimer's disease. Acta neuropathologica 80:581-589. CrossRef Medline

Vogt BA, Vogt LJ, Vrana KE, Gioia L, Meadows RS, Challa VR, Hof PR, Van Hoesen GW (1998) Multivariate analysis of laminar patterns of neurodegeneration in posterior cingulate cortex in Alzheimer's disease. Exp Neurol 153:8-22. CrossRef Medline

Webb PG, Sailasuta N, Kohler SJ, Raidy T, Moats RA, Hurd RE (1994) Automated single-voxel proton MRS: technical development and multisite verification. Magnetic Resonance in Medicine 31:365-373. CrossRef Medline

Whitwell JL, Josephs KA, Murray ME, Kantarci K, Przybelski SA, Weigand SD, Vemuri P, Senjem ML, Parisi JE, Knopman DS, Boeve BF, Petersen RC, Dickson DW, Jack CR Jr (2008) MRI correlates of neurofibrillary tangle pathology at autopsy: a voxel-based morphometry study. Neurology 71:743-749. CrossRef Medline

Yen SH, Dickson DW, Crowe A, Butler M, Shelanski ML (1987) Alzheimer's neurofibrillary tangles contain unique epitopes and epitopes in common with the heat-stable microtubule associated proteins tau and MAP2. Am J Pathol 126:81-91. Medline 